\title{
Transversus abdominal plane block for postoperative analgesia: a systematic review and meta-analysis of randomized-controlled trials
}

\section{Le bloc dans le plan du muscle transverse de l'abdomen pour réaliser une analgésie postopératoire: revue systématique et méta-analyse des études randomisées contrôlées}

\author{
Etrusca Brogi, MD • Roy Kazan, MD - Shantale Cyr, PhD • Francesco Giunta, MD • \\ Thomas M. Hemmerling, MD \\ Received: 17 March 2015/Revised: 25 April 2016/Accepted: 1 June 2016/Published online: 15 June 2016 \\ (C) Canadian Anesthesiologists' Society 2016
}

\begin{abstract}
Purpose The transversus abdominal plane (TAP) block has been described as an effective pain control technique after abdominal surgery. We performed a systematic review and meta-analysis of randomized-controlled trials (RCTs) to account for the increasing number of TAP block studies appearing in the literature. The primary outcome we examined was the effect of TAP block on the postoperative pain score at six, 12, and $24 \mathrm{hr}$. The secondary outcome was 24-hr morphine consumption.

Source We searched the United States National Library of Medicine database, the Excerpta Medica database, and the Cochrane Central Register of Controlled Clinical Studies and identified RCTs focusing on the analgesic efficacy of TAP block compared with a control group [i.e., placebo,
\end{abstract}

E. Brogi, MD - F. Giunta, MD

Department of Anesthesia and Intensive Care, University of Pisa, Pisa, Italy

R. Kazan, MD - S. Cyr, PhD - T. M. Hemmerling, MD Division of Experimental Surgery, McGill University, Montreal, QC, Canada

S. Cyr, PhD - T. M. Hemmerling, MD

Department of Anesthesia, McGill University, Montreal,

QC, Canada

T. M. Hemmerling, MD

Institute of Biomedical Engineering, University of Montreal,

Montreal, QC, Canada

T. M. Hemmerling, MD ( $₫)$

Department of Anesthesia, Montreal General Hospital, C10-153,

1650 Cedar Avenue, Montreal, QC H3G 1A4, Canada

e-mail: thomas.hemmerling@mcgill.ca epidural analgesia, intrathecal morphine (ITM), and ilioinguinal nerve block after abdominal surgery]. Meta-analyses were performed on postoperative pain scores at rest at six, 12, and $24 \mathrm{hr}$ (visual analogue scale, 0-10) and on 24-hr opioid consumption.

Principal findings In the 51 trials identified, compared with placebo, TAP block reduced the VAS for pain at six hours by 1.4 (95\% confidence interval [CI], -1.9 to $-0.8 ; P<0.001)$, at $12 \mathrm{hr}$ by $2.0(95 \% \mathrm{CI},-2.7$ to $-1.4 ; \mathrm{P}<0.001)$, and at $24 \mathrm{hr}$ by 1.2 (95\% CI, -1.6 to $-0.8 ; P<0.001)$. Similarly, compared with placebo, TAP block reduced morphine consumption at $24 \mathrm{hr}$ after surgery (mean difference, -14.7 mg; 95\% CI, -18.4 to $-11.0 ; P<0.001$ ). We observed this reduction in pain scores and morphine consumption in the TAP block group after gynecological surgery, appendectomy, inguinal surgery, bariatric surgery, and urological surgery. Nevertheless, separate analysis of the studies comparing ITM with TAP block revealed that ITM seemed to have a greater analgesic efficacy.

Conclusions The TAP block can play an important role in the management of pain after abdominal surgery by reducing both pain scores and 24-hr morphine consumption. It may have particular utility when neuraxial techniques or opioids are contraindicated.

\section{Résumé}

Objectif Le bloc dans le plan du muscle transverse de l'abdomen (ou TAP bloc) a été décrit comme une technique efficace de contrôle de la douleur après une chirurgie abdominale. Nous avons réalisé une revue systématique et une méta-analyse des études randomisées contrôlées (ERC) pour faire un état des lieux du nombre croissant d'études 
sur le TAP bloc qui s'ajoutent à la littérature. Le critère d'évaluation principal était l'effet d'un TAP bloc sur les scores de douleur postopératoire à six, 12 et $24 \mathrm{~h}$. Le critère d'évaluation secondaire était la consommation de morphine à $24 \mathrm{~h}$.

Source Nous avons effectué des recherches dans la base de données de la Bibliothèque nationale américaine de médecine (United States National Library of Medicine) ainsi que dans le Registre central Cochrane des études cliniques contrôlées (Cochrane Central Register of Controlled Clinical Studies). Nous avons ensuite identifié les ERC se concentrant sur l'efficacité analgésique des TAP blocs par rapport à un groupe témoin [c.-à-d. placebo, analgésie péridurale, morphine intrathécale (MIT) et bloc nerveux ilio-inguinal] après une chirurgie abdominale. Des méta-analyses ont été réalisées en examinant les scores de douleur postopératoire au repos à six, 12 et 24 h (échelle visuelle analogique [EVA], 0-10) et la consommation d'opiö̈des sur une période de $24 \mathrm{~h}$.

Constatations principales Parmi les 51 études identifiées, par rapport à un placebo, le TAP bloc a réduit le score de douleur de 1,4 sur l'EVA après six heures (intervalle de confiance [IC] $95 \%,-1,9$ à -0,8; $P<0,001)$, de 2,0 après $12 h$ (IC $95 \%,-2,7$ à -1,4; $P<0,001)$ et de 1,2 après 24 h (IC $95 \%$, -1,6 à-0,8; P<0,001). De la même façon, par rapport au placebo, le TAP bloc a réduit la consommation de morphine à $24 \mathrm{~h}$ après la chirurgie (différence moyenne, -14,7 mg; IC 95\%, -18,4 à -11,0; $P<0,001)$. Nous avons observé cette réduction en matière de scores de douleur et de consommation de morphine dans le groupe TAP bloc après des chirurgies gynécologiques, des appendicectomies, des chirurgies inguinales, des chirurgies bariatriques et des chirurgies urologiques. Toutefois, une analyse séparée des études comparant la MIT au TAP bloc a révélé que la MIT semblait avoir une efficacité analgésique plus prononcée.

Conclusion Le TAP bloc peut jouer un rôle important dans la prise en charge de la douleur après une chirurgie abdominale en réduisant les scores de douleur et la consommation de morphine à $24 \mathrm{~h}$. Il pourrait être particulièrement utile lorsque l'utilisation de techniques neuraxiales ou les opiö̈des sont contre-indiqués.

The first description of the transversus abdominal plane (TAP) block consisted of a loss-of-resistance technique with the local anesthetic administered into the triangle of Petit (i.e., the area confined within the iliac crest, the latissimus dorsi, and the external abdominal oblique muscle). ${ }^{1}$ Since then, numerous variations of this approach have been suggested to overcome the significant variability of local anesthetic spread demonstrated in cadaveric studies. ${ }^{2-4}$
In recent years, TAP block has gained popularity as an effective pain relief technique in patients undergoing a variety of abdominal operations. An increasing number of randomized-controlled trials (RCTs) and case reports in the literature have highlighted the analgesic effectiveness of the TAP block and proposed it as an alternative pain management technique in patients with contraindications to the use of opioids and/or neuraxial anesthesia. Indeed, TAP block avoids the risk of neuraxial complications in all patients.

Previous reviews and meta-analyses have all had some limitations. For example, these prior reports have included a relatively small number of studies that were often limited to very specific surgical settings. For example, a 2010 Cochrane Review of the analgesic effectiveness of TAP block after abdominal surgery included only five trials. ${ }^{5}$ In 2012, Abdallah et al. subsequently reported a systematic review and meta-analysis of TAP block for pain relief after Cesarean delivery that included results from five trials, ${ }^{6}$ and in 2013, Champaneria et al. ${ }^{7}$ performed a similar meta-analysis of five trials of TAP block after hysterectomy. A more recent and larger metaanalysis from $2013^{8}$ included ten RCTs of TAP block but was restricted to only laparoscopic surgery. Since then, numerous TAP block RCTs have been published warranting an updated review.

In this systematic review and meta-analysis, we address the analgesic efficacy of TAP blocks after abdominal surgery. The primary outcome is the difference in postoperative pain scores at rest at six, 12, and $24 \mathrm{hr}$ in patients following abdominal surgery with either a TAP block or an alternative analgesic technique (i.e., placebo, epidural analgesia, intrathecal morphine (ITM), ilioinguinal or iliohypogastric nerve block (IIN), and wound infiltration). The secondary endpoint examined was 24-hr morphine consumption.

\section{Methods}

The authors followed the PRISMA (Preferred Reporting Items for Systematic Reviews and Meta-Analyses) statements in preparing this review. ${ }^{9}$

The studies were retrieved from the United States National Library of Medicine database (MEDLINE ${ }^{\circledR}$ ), the Excerpta Medica database (EMBASE ${ }^{\mathrm{TM}}$ ), and Cochrane Central Register of Controlled Clinical Studies (CENTRAL). The search criteria were ([transversus abdominis plane block]) AND ([analgesic efficacy] OR [analgesic effectiveness] OR [postoperative pain relief]) AND ([surgery] OR [abdominal surgery] OR [laparoscopic surgery]), without any restrictions for language. Databases were explored from January 1, 2004 to August 31, 2014. In addition, we conducted a hand search through the reference lists to identify any studies missed by the electronic search. 
Our search was limited to published RCTs on human subjects comparing TAP block with placebo (i.e., saline or no block), epidural analgesia, ITM local infiltration, and other nerve blocks. Reviews, abstracts, letters to editors, meta-analyses, case reports, and retrospective studies were excluded. The authors screened the search results and removed duplicates. Complete paper copies were obtained for all studies not eliminated for irrelevance to the subject.

Exclusion criteria were studies of irrelevance to TAP block, technical descriptions/proceedings, studies in volunteers, dose-ranging studies of anesthetics, cadaveric evaluation of anesthetic spread, and studies that compared TAP block with anesthetic techniques not mentioned above. Studies were also excluded if they did not report postoperative pain scores at six, 12, or $24 \mathrm{hr}$, total analgesic consumption at $24 \mathrm{hr}$, or if the authors did not specify the time at which the data were recorded.

The selected articles were evaluated using the three-item five-point Jadad quality scale. ${ }^{10}$ The score ranges from $0-5$, and studies with low-quality scores (0-2) were not included.

A data collection sheet was created and data were extracted on anesthesia technique, type of surgery, American Society of Anesthesiologists physical status classification, TAP block technique (ultrasound-guided or landmark), timing of the block, site of injection, postoperative analgesia regimen, pain intensity scores at rest, opioid consumption, and side effects (nausea, vomiting, and sedation). One investigator (E.B.) was in charge of collecting the data and assessing the methodological validity of all the eligible studies. All data were then verified by two further investigators (S.C., T.M.).

The data were extracted from the articles retrieved using the Cochrane Handbook for Systematic Reviews of Interventions ${ }^{1}$ and recommendations by Hozo et al. ${ }^{11}$ Our primary outcome was a comparison of postoperative pain scores at rest between TAP block and control analgesic technique, measured by a visual or numerical scale (0-10 scale, where $0=$ no pain and 10 $=$ worst pain imaginable) at six, 12, and $24 \mathrm{hr}$. Any visual analogue scale (VAS) scores reported on a 0-100 scale were converted to a 0-10 scale for analysis. The secondary outcome was 24-hr opioid consumption. Any opiate drugs other than intravenous morphine where converted to morphine equivalents. $^{12,13}$ The endpoints were then examined by performing individual statistical analyses based on the type of surgery (i.e., Cesarean delivery, gynecological surgery, abdominal surgery).

If trials included more than two groups for comparison, in the final analysis, we included only the group that received a TAP block and the group that received the interventional procedure (i.e., epidural, ITM, wound infiltration, other nerve blocks). Trials were not included in the meta-analysis if data were not reported at the time selected as our primary outcome or if opioids were not used as analgesic drugs. We included only those studies that collected and reported total 24-hr opioid consumption (in $\mathrm{mg}$ ) and that specified the time of data collection.

Publication bias was evaluated by analyzing the funnel plots. ${ }^{14}$ Continuous data were summarized as mean (standard deviation, [SD]). The mean difference and the standardized mean differences with a $95 \%$ confidence interval (CI) were calculated. We used random effects modelling to analyse the data. Heterogeneity of the retrieved trials was evaluated using the $\mathrm{I}^{2}$ statistic (where $\mathrm{I}^{2}>75 \%$ reflects a high heterogeneity). We performed subgroup analyses according to the TAP block technique (i.e., ultrasound, landmark technique, from inside the abdominal wall) as sensitivity analysis for the primary and secondary endpoints. Meta-analyses and subanalyses were performed when at least two trials reported our selected endpoints. All statistical analyses were performed using Review Manager (RevMan) Computer program Version 5.3 (Copenhagen: The Nordic Cochrane Centre, The Cochrane Collaboration, 2012). We also evaluated the quality of evidence for the outcomes reported in our systematic review and meta-analysis using the Grading of Recommendations Assessment, Development and Evaluation (GRADE) system. ${ }^{15}$

\section{Results}

A flowchart of the literature search is shown in Fig. 1. Electronic literature searches identified 406 articles, which fulfilled the criteria of the review outlined above. Twelve further citations were found by hand searching. Duplicate studies were removed and the remaining articles were screened by abstract and titles for eligibility. From these citations, 72 full-text articles were obtained, and 21 studies were excluded after a more detailed inspection. Reasons for exclusion were irrelevance to the topic, retrospective studies, studies not randomized, cadaveric models, volunteer models, Jadad score 0-2, opioid consumption not collected, and studies that included only technical descriptions.

Our search retrieved 51 RCTs that satisfied our inclusion criteria. Characteristics of these articles are reported in Table 1 . In the majority (36 of the 51 ) of the studies, TAP blocks were performed using ultrasound (US) guidance. In three studies, the injection of local anesthetic into the TAP was performed from inside the abdominal wall. ${ }^{16-18}$ The remaining 12 studies used a non-US-guided loss-ofresistance technique. Tables 2 and 3 provide a summary of the statistical analysis (i.e., mean VAS differences, CI, $P$ value, heterogeneity scores, and quality of the evidence [GRADE]) for each of the subcategories of TAP block use described below. 


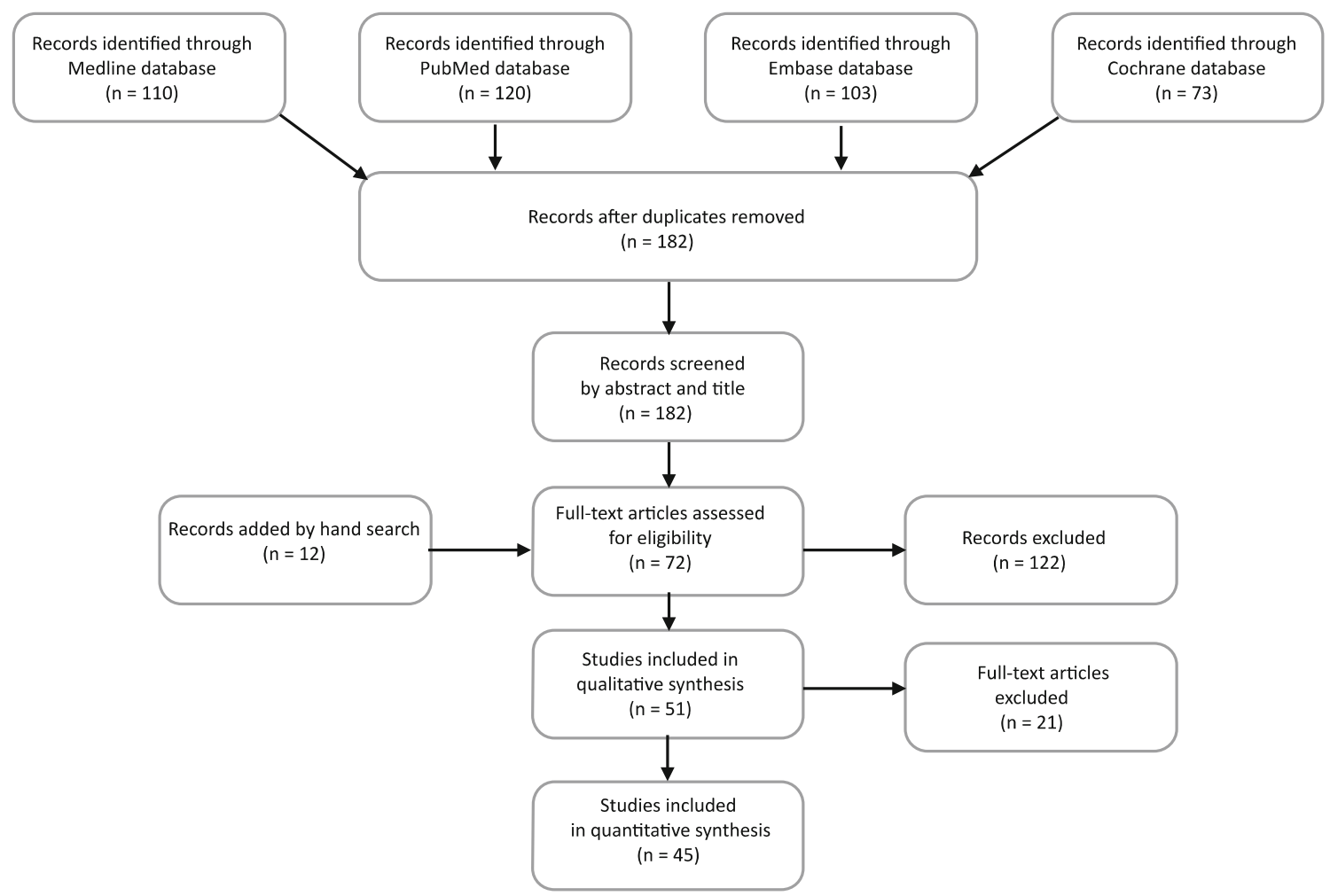

Fig. 1 PRISMA (Preferred Reporting Items for Systematic Reviews and Meta-Analyses) flowchart summarizing retrieved, included, and excluded trials

Transversus abdominal plane block vs placebo

We identified 36 RCTs comparing TAP blocks with placebo (Table 2). Pain scores at six and $12 \mathrm{hr}$ were investigated in $23^{17-39}$ and $18^{16-23,25,26,29,31,32,34-36,38-41}$ studies, respectively. The overall analyses showed that, in the TAP block group, the six-hour VAS pain score was reduced by $1.4(95 \% \mathrm{CI},-1.9$ to $-0.8 ; P<0.001$ ) (Fig. 2), and the 12-hr pain score was reduced by 2 (95\% CI, -2.7 to $-1.4 ; P<0.001)$ (Fig. 3). Heterogeneity was high $\left(\mathrm{I}^{2}=0.94\right.$, for both outcomes; Table 2$)$. Thirty-three studies investigated the pain score at $24 \mathrm{hr}$ and found a reduction of $1.2(95 \% \mathrm{CI},-1.6$ to $-0.8 ; P<0.001)$ in the TAP block group $\left(\mathrm{I}^{2}=0.93\right)$. Consumption of opioids at 24 hr after surgery was investigated in 28 studies, with a significant reduction in opioid intake of $14.7 \mathrm{mg}(95 \% \mathrm{CI}$, -18.4 to $-11.0 ; P<0.001$ ) in the TAP block group (Table 2 ).

Subgroup analyses of TAP block studies using only landmark, US guidance, or inside the abdominal wall approaches are presented in Table 3. They similarly showed reductions in VAS scores and opioid consumption.

Transversus abdominal plane block vs epidural analgesia

Only three studies ${ }^{41-43}$ addressed the comparison between TAP block and epidural anesthesia, and none of them showed any significant differences between the two techniques (Table 2). Only one $\mathrm{RCT}^{43}$ investigated eight-hour pain score, and one trial $^{43}$ reported the 24-hr morphine consumption. It was not possible to perform subgroup analysis for this comparison.

Transversus abdominal plane block vs intrathecal morphine

Four studies examined the analgesic efficacy of TAP block in comparison with ITM in women scheduled for Cesarean delivery. ${ }^{44-47}$ Use of ITM also reduced VAS score by 0.7 (95\% CI, 0.3 to $1.1 ; P=0.001$ ) at six hours. Only one trial $^{45}$ evaluated the $12-\mathrm{hr}$ pain score. All four trials investigated 24-hr pain scores; there was no statistical difference in the VAS scores obtained using ITM $v s$ TAP block (Table 2). Intrathecal morphine, however, showed significantly reduced opioid consumption ${ }^{44,46,47}$ by $7.7 \mathrm{mg}$ (95\% CI, -1.9 to $-13.5 ; P=0.009$ ) in comparison with TAP block (Table 2). It was not possible to perform subgroup analysis for this comparison.

Transversus abdominal plane block vs ilioinguinal/ iliohypogastric nerve block

We identified only two articles comparing TAP block with IIN block. In one study, ${ }^{48} 273$ adults scheduled for 
Table 1 Characteristics of eligible studies $(n=51)$

\begin{tabular}{|c|c|c|c|}
\hline Characteristics & $n$ & Characteristics & $n$ \\
\hline Age & & Postoperative analgesia regimen & \\
\hline Adults ${ }^{17-20,22-49,51-53,55-64,66}$ & 46 & Intravenous morphine ${ }^{18,20,30,31,34,39,45,48,49,52,55,63}$ & 12 \\
\hline Pediatrics ${ }^{20,49,53,64,69}$ & 5 & PCA morphine ${ }^{19-21,23,25-29,35-37,39,41,43,46,47,51,54,60,62,65,69}$ & 23 \\
\hline ASA score: & & PCA fentanyl ${ }^{38}$ & 1 \\
\hline $\mathrm{I}-\mathrm{III}^{16-18,20-24,26-30,32,34,35,37-44,46-58,62-65,69}$ & 43 & NSAIDs ${ }^{16,17,20-22,28,29,31,32,41,44,45,47-49,52,56-58,61,62}$ & 21 \\
\hline Not reported ${ }^{19,25,33,36,45,59-61}$ & 8 & Acetaminophen ${ }^{17,20,22,25,26,28,30,31,34,36,41,44,45,47-49,51-53,56-60,62-65,69}$ & 46 \\
\hline Type of surgery & & TAP block technique & \\
\hline Cesarean delivery $22,24,27,28,34,35,44-47,56,57$ & 12 & $\mathrm{US}^{22,23,26,27,32-46,48-53,55-57,59-65,69}$ & 36 \\
\hline Gynecological procedures ${ }^{17,21,26,32,50,51,54,58-61}$ & 11 & Landmark $^{19-21,24,25,28-31,47,54,58}$ & 12 \\
\hline Cholecystectomy ${ }^{52,55}$ & 2 & From inside the abdominal wall ${ }^{16-18}$ & 3 \\
\hline Appendectomy $y^{20,30,62,69}$ & 4 & Type of block & \\
\hline Inguinal hernia repair ${ }^{30,31,39,48,49,53}$ & 6 & Single injections ${ }^{16-38,40,43-50,52-65,69}$ & 47 \\
\hline Bariatric surgery ${ }^{33,37,63}$ & 3 & Continuous ${ }^{39,41,42,51}$ & 4 \\
\hline Liver resection ${ }^{38,42}$ & 2 & Site of injection & \\
\hline Gastrectomy $^{43}$ & 1 & Bilateral $^{16-19,21-24,26-29,32-38,41-47,50-52,54,56-61,63}-65$ & 40 \\
\hline Urological surgery ${ }^{19,23,25,40,64,65}$ & 6 & Unilateral $^{20,25,30,31,39,48,49,53,55,62,69}$ & 11 \\
\hline Bowel resection ${ }^{16,29,36,41}$ & 4 & Timing of the bock & \\
\hline Comparator Group & & Before surgery ${ }^{17-21,23,25,26,29,30,32,36,38-40,43,48-50,52-55,59,62-65,69}$ & 29 \\
\hline TAP vs placebo ${ }^{16-40,56-65,69}$ & 36 & End of surgery ${ }^{16,24,27,28,31,33-35,37,41,42,44-47,51,56-61}$ & 22 \\
\hline TAP $v s$ epidural $^{41-43}$ & 3 & Jadad score & \\
\hline TAP vs ITM ${ }^{44-47}$ & 4 & $5^{23,24,45,57,59,60,63,65}$ & 8 \\
\hline TAP $v s \operatorname{IIN}^{48,49}$ & 2 & $4^{16-22,25,26,28,29,31,33,35,36,47,48,50,52-54,56,58,62}$ & 24 \\
\hline TAP vs local infiltration ${ }^{50-55}$ & 6 & $3^{27,30,32,34,37-44,46,49,51,55,61,64,69}$ & 19 \\
\hline Anesthesia technique & & Other outcomes investigated & \\
\hline General $^{16-69}$ & 40 & PONV $16,19-23,25-29,32,34-36,38-48,50-53,56,57,59,60,62-65,69$ & 39 \\
\hline Spinal $^{22,27,28,31,34,44-47,56,57}$ & 11 & Sedation ${ }^{16,19-21,25-30,32-35,38,39,43-47,50,51,54,56,60,65,69}$ & 28 \\
\hline
\end{tabular}

ASA = American Society of Anesthesiologists; IIN = ilioinguinal/iliohypogastric nerve block; ITM = intrathecal morphine; NSAIDs = nonsteroidal anti-inflammatory drugs; $\mathrm{PCA}=$ patient-controlled analgesia; $\mathrm{PONV}=$ postoperative nausea and vomiting; $\mathrm{TAP}=$ transversus abdominal plane block; US = ultrasound

inguinal hernia repair were randomly allocated to receive either US-guided TAP block or IIN block by a loss-ofresistance technique. Patients who received TAP block expressed significantly less pain at $12 \mathrm{hr}(P=0.001)$ and $24 \mathrm{hr}(P=0.013)$. Pain scores after the first $24 \mathrm{hr}$ were similar in both groups. Postoperative morphine requirements were lower during the first $24 \mathrm{hr}$ after surgery in the TAP block group $(P=0.030)$. The other study involving 41 children $^{49}$ found a higher number of patients reporting pain in the TAP block group $v s$ the IIN group (76\% vs $45 \%$, respectively; $P=0.040)$ and a higher rate of analgesic consumption (62\% vs $30 \%$, respectively; $P=0.037)$.

Transversus abdominal plane block vs local infiltration

Six studies ${ }^{50-55}$ investigated the efficacy of TAP block $v s$ local anesthetic infiltration at the wound site. Compared with local infiltration, TAP block significantly reduced the six-hour VAS pain score ${ }^{50,51,54}$ by $1.4(95 \% \mathrm{CI},-2.2$ to $-0.6 ; P<0.001)$; however, this difference was not significant at $12 \mathrm{hr}^{52,53}$ and $24 \mathrm{hr}^{51-53,55}$ (Table 2). The TAP block significantly reduced 24-hr morphine consumption by $5.0 \mathrm{mg}(95 \% \mathrm{CI},-9.5$ to $-0.5 ; P=$ 0.004) (Table 2). It was not possible to perform subgroup analysis for this comparison.

Transversus abdominal plane block for Cesarean delivery

Twelve studies $22,24,27,28,34,35,44-47,56,57$ evaluated the use of TAP block for Cesarean delivery. Nine trials $^{22,24,28,29,34,35,44,46,47}$ reported the six-hour pain score and six RCTs $^{22,24,28,34,35,47}$ investigated the 12-hr pain score. Compared with the control group, the overall analysis showed that the TAP block did not reduce VAS scores at six hour but reduced the VAS score by $1.5(-2.3$ 
Table 2 Summary of visual analogue pain score differences and differences in opioid consumption in patients receiving TAP block

\begin{tabular}{|c|c|c|c|c|c|c|c|c|}
\hline Comparison & $\begin{array}{l}\text { Pain / } \\
\text { Opioids }\end{array}$ & Time & $\begin{array}{l}n \text { of studies } \\
\text { involved }\end{array}$ & $\begin{array}{l}\text { Mean } \\
\text { difference }\end{array}$ & $95 \% \mathrm{CI}$ & $P$ value & $\mathrm{I}^{2}$ & $\begin{array}{l}\text { Quality of the } \\
\text { evidence (GRADE) }\end{array}$ \\
\hline TAP block vs Placebo & Pain & $6 \mathrm{hr}$ & 23 & -1.37 & -1.94 to -0.81 & $P<0.001$ & 0.94 & moderate +++ \\
\hline TAP block vs Placebo & Pain & $12 \mathrm{hr}$ & 18 & -2.04 & -2.72 to -1.37 & $P<0.001$ & 0.94 & moderate +++ \\
\hline TAP block vs Placebo & Pain & $24 \mathrm{hr}$ & 33 & -1.17 & -1.58 to -0.75 & $P<0.001$ & 0.93 & moderate +++ \\
\hline TAP block vs Placebo & Opioids & $24 \mathrm{hr}$ & 28 & -14.68 & -18.40 to -10.95 & $P<0.001$ & 0.99 & moderate +++ \\
\hline TAP block vs Epidural & Pain & $6 \mathrm{hr}$ & 2 & +0.59 & -0.57 to 1.75 & $P=0.32$ & 0.89 & very low + \\
\hline TAP block vs Epidural & Pain & $24 \mathrm{hr}$ & 3 & +1.29 & -0.61 to 3.18 & $P=0.18$ & 0.97 & very low + \\
\hline TAP block vs ITM & Pain & $6 \mathrm{hr}$ & 3 & +0.69 & 0.28 to 1.11 & $P=0.001$ & 0.40 & moderate +++ \\
\hline TAP block $v s$ ITM & Pain & $24 \mathrm{hr}$ & 4 & +0.45 & -0.06 to 0.95 & $P=0.08$ & 0.69 & moderate +++ \\
\hline TAP block $v s$ ITM & Opioids & $24 \mathrm{hr}$ & 3 & +7.67 & 1.89 to 13.45 & $P=0.009$ & 0.86 & high ++++ \\
\hline TAP block $v s$ LI & Pain & $6 \mathrm{hr}$ & 3 & -1.39 & -2.20 to -0.57 & $P<0.001$ & 0.78 & low ++ \\
\hline TAP block vs LI & Pain & $12 \mathrm{hr}$ & 2 & -2.94 & -7.63 to 1.76 & $P=0.22$ & 0.99 & low ++ \\
\hline TAP block $v s$ LI & Pain & $24 \mathrm{hr}$ & 4 & -0.75 & -2.23 to 0.73 & $P=0.32$ & 0.96 & low ++ \\
\hline TAP block vs LI & Opioids & $24 \mathrm{hr}$ & 3 & -4.96 & -9.45 to -0.48 & $P=0.004$ & 0.82 & low ++ \\
\hline TAP block for CD & Pain & $6 \mathrm{hr}$ & 9 & -0.71 & -1.54 to 0.12 & $P=0.09$ & 0.94 & moderate +++ \\
\hline TAP block for CD & Pain & $12 \mathrm{hr}$ & 6 & -1.50 & -2.33 to -0.66 & $P<0.001$ & 0.91 & high ++++ \\
\hline TAP block for CD & Pain & $24 \mathrm{hr}$ & 12 & -0.18 & -0.57 to 0.21 & $P=0.37$ & 0.83 & moderate +++ \\
\hline TAP block for CD & Opioids & $24 \mathrm{hr}$ & 11 & -10.1 & -17.35 to -2.82 & $P=0.006$ & 0.99 & high ++++ \\
\hline TAP block for GS & Pain & $6 \mathrm{hr}$ & 7 & -1.18 & -1.75 to -0.62 & $P<0.001$ & 0.79 & moderate +++ \\
\hline TAP block for GS & Pain & $12 \mathrm{hr}$ & 3 & -1.13 & -1.95 to -0.31 & $P=0.007$ & 0.80 & moderate +++ \\
\hline TAP block for GS & Pain & $24 \mathrm{hr}$ & 11 & -1.13 & -2.06 to -0.21 & $P<0.001$ & 0.96 & moderate +++ \\
\hline TAP block for GS & Opioids & $24 \mathrm{hr}$ & 8 & -5.86 & -8.60 to -3.10 & $P<0.001$ & 0.81 & moderate +++ \\
\hline TAP block for AS & Pain & $6 \mathrm{hr}$ & 6 & -0.04 & -1.35 to 1.27 & $P=0.95$ & 0.96 & low ++ \\
\hline TAP block for AS & Pain & $12 \mathrm{hr}$ & 4 & -1.90 & -4.21 to 0.41 & $P=0.11$ & 0.98 & low ++ \\
\hline TAP block for AS & Pain & $24 \mathrm{hr}$ & 8 & -0.83 & -2.05 to 0.39 & $P=0.18$ & 0.97 & low ++ \\
\hline TAP block for AS & Opioids & $24 \mathrm{hr}$ & 6 & -14.67 & -37.78 to 8.43 & $P=0.21$ & 0.99 & moderate +++ \\
\hline TAP block for App/IS & Pain & $6 \mathrm{hr}$ & 4 & -2.49 & -4.70 to -1.17 & $P=0.001$ & 0.94 & moderate +++ \\
\hline TAP block for App/IS & Pain & $12 \mathrm{hr}$ & 5 & -3.92 & -4.98 to -2.86 & $P<0.001$ & 0.88 & moderate +++ \\
\hline TAP block for App/IS & Pain & $24 \mathrm{hr}$ & 6 & -1.67 & -2.38 to -0.96 & $P<0.001$ & 0.89 & low ++ \\
\hline TAP block for App/IS & Opioids & $24 \mathrm{hr}$ & 3 & -20.37 & -29.70 to -11.05 & $P<0.001$ & 0.77 & moderate +++ \\
\hline TAP block for BS & Pain & $6 \mathrm{hr}$ & 2 & -0.91 & -1.33 to -0.49 & $P<0.001$ & 0.16 & moderate +++ \\
\hline TAP block for BS & Pain & $12 \mathrm{hr}$ & 2 & -1.07 & -1.58 to -0.56 & $P<0.001$ & 0.36 & moderate +++ \\
\hline TAP block for BS & Pain & $24 \mathrm{hr}$ & 3 & -0.55 & -2.08 to 0.98 & $P=0.48$ & 0.95 & low ++ \\
\hline TAP block for BS & Opioids & $24 \mathrm{hr}$ & 3 & -3.80 & -5.48 to -2.17 & $P<0.001$ & 0.33 & moderate +++ \\
\hline TAP block for Urol.S & Pain & $6 \mathrm{hr}$ & 3 & -0.04 & -0.85 to 0.78 & $P=0.93$ & 0.76 & low ++ \\
\hline TAP block for Urol.S & Pain & $12 \mathrm{hr}$ & 3 & -2.59 & -5.91 to 0.74 & $P=0.13$ & 0.97 & low ++ \\
\hline TAP block for Urol.S & Pain & $24 \mathrm{hr}$ & 5 & -0.89 & -2.05 to 0.27 & $P=0.13$ & 0.93 & low ++ \\
\hline TAP block for Urol.S & Opioids & $24 \mathrm{hr}$ & 4 & -14.20 & -30.59 to 2.18 & $P=0.09$ & 0.99 & low ++ \\
\hline
\end{tabular}

App/IS = appendectomy /inguinal surgery; $\mathrm{AS}=$ abdominal surgery; $\mathrm{BS}=$ bariatric surgery; $\mathrm{CD}=$ Cesarean delivery; $\mathrm{CI}=$ confidence interval; $\mathrm{GS}=$ gynecological surgery; $\mathrm{I}^{2}=$ heterogeneity; ITM = intrathecal morphine; LI = local infiltration; TAP = transversus abdominal plane block; Urol S = urological surgery

to $-0.7 ; P<0.001$ ) at $12 \mathrm{hr}$ (Fig. 4). All the studies reported the 24-hr pain score, and 11 trials documented the 24-hr morphine consumption. . $^{2,24,27,29,34,35,44,46,47,56,57}$ Transversus abdominal plane block did not significantly reduce the pain score (Table 2) at $24 \mathrm{hr}$ but significantly reduced the mean 24-hr opioid consumption by $10 \mathrm{mg}$ (95\% CI, -17.4 to $-2.8 ; P=0.006$ ) compared with the control group (Table 2). The US-guided and landmark subgroup analyses for Cesarean delivery studies are presented in Table 3. 
Table 3 Summary of the visual analogue pain score results and results in opioid consumption in the subgroup analysis

\begin{tabular}{|c|c|c|c|c|c|c|c|c|c|}
\hline Comparison & $\begin{array}{l}\text { Pain / } \\
\text { Opioids }\end{array}$ & Time & Subgroups & $\begin{array}{l}n \text { of studies } \\
\text { involved }\end{array}$ & $\begin{array}{l}\text { Mean } \\
\text { difference }\end{array}$ & $95 \% \mathrm{CI}$ & $P$ value & $\mathrm{I}^{2}$ & $\begin{array}{l}\text { Quality of the } \\
\text { evidence (GRADE) }\end{array}$ \\
\hline TAP block vs Placebo & Pain & $6 \mathrm{hr}$ & US & 12 & -0.92 & -1.66 to -0.18 & $P=0.01$ & 0.94 & moderate +++ \\
\hline TAP block $v s$ Placebo & Pain & $6 \mathrm{hr}$ & Landmark & 9 & -2.07 & -3.20 to -0.93 & $P<0.001$ & 0.95 & moderate +++ \\
\hline TAP block vs Placebo & Pain & $6 \mathrm{hr}$ & IAW & 2 & -1.06 & -1.54 to -0.59 & $P<0.001$ & 0.00 & moderate +++ \\
\hline TAP block vs Placebo & Pain & $12 \mathrm{hr}$ & US & 9 & -2.13 & -3.13 to -1.12 & $P<0.001$ & 0.95 & moderate +++ \\
\hline TAP block vs Placebo & Pain & $12 \mathrm{hr}$ & Landmark & 7 & -2.15 & -3.39 to -0.91 & $P<0.001$ & 0.95 & moderate +++ \\
\hline TAP block vs Placebo & Pain & $12 \mathrm{hr}$ & IAW & 2 & -1.42 & -2.44 to -0.41 & $P<0.001$ & 0.74 & moderate +++ \\
\hline TAP block $v s$ Placebo & Pain & $24 \mathrm{hr}$ & US & 22 & -1.04 & -1.53 to -0.54 & $P<0.001$ & 0.93 & moderate +++ \\
\hline TAP block $v s$ Placebo & Pain & $24 \mathrm{hr}$ & Landmark & 9 & -1.51 & -2.36 to -0.67 & $P<0.001$ & 0.94 & moderate +++ \\
\hline TAP block $v s$ Placebo & Pain & $24 \mathrm{hr}$ & IAW & 2 & -0.94 & -1.51 to -0.36 & $P=0.001$ & 0.33 & moderate +++ \\
\hline TAP block $v s$ Placebo & Opioids & $24 \mathrm{hr}$ & US & 20 & -12.93 & -17.58 to -8.28 & $P<0.001$ & 0.99 & moderate +++ \\
\hline TAP block vs Placebo & Opioids & $24 \mathrm{hr}$ & Landmark & 6 & -23.83 & -39.5 to -8.16 & $P=0.003$ & 0.99 & moderate +++ \\
\hline TAP block $v s$ Placebo & Opioids & $24 \mathrm{hr}$ & IAW & 2 & -7.61 & -14.57 to -0.65 & $P=0.03$ & 0.89 & moderate +++ \\
\hline TAP block for CD & Pain & $6 \mathrm{hr}$ & US & 6 & -0.39 & -1.09 to 0.30 & $P=0.27$ & 0.90 & moderate +++ \\
\hline TAP block for CD & Pain & $6 \mathrm{hr}$ & Landmark & 3 & -1.35 & -3.98 to 1.29 & $P=0.32$ & 0.97 & moderate +++ \\
\hline TAP block for CD & Pain & $12 \mathrm{hr}$ & US & 4 & -1.30 & -2.40 to -0.20 & $P=0.02$ & 0.93 & high ++++ \\
\hline TAP block for CD & Pain & $12 \mathrm{hr}$ & Landmark & 2 & -1.92 & -2.40 to -1.43 & $P<0.001$ & 0.00 & high ++++ \\
\hline TAP block for CD & Pain & $24 \mathrm{hr}$ & US & 9 & -0.11 & -0.42 to 0.21 & $P=0.5$ & 0.68 & moderate +++ \\
\hline TAP block for CD & Pain & $24 \mathrm{hr}$ & Landmark & 3 & -0.33 & -1.91 to 1.25 & $P=0.68$ & 0.95 & moderate +++ \\
\hline TAP block for CD & Opioids & $24 \mathrm{hr}$ & US & 8 & -9.31 & -17.43 to -1.19 & $P<0.001$ & 0.99 & high ++++ \\
\hline TAP block for CD & Opioids & $24 \mathrm{hr}$ & Landmark & 3 & -11.91 & -39.31 to -15.48 & $P<0.001$ & 0.98 & moderate +++ \\
\hline TAP block for App/IS & Pain & $12 \mathrm{hr}$ & US & 2 & -4.74 & -6.72 to -2.76 & $P<0.001$ & 0.86 & moderate +++ \\
\hline TAP block for App/IS & Pain & $12 \mathrm{hr}$ & Landmark & 3 & -3.43 & -5.10 to -1.75 & $P<0.001$ & 0.88 & moderate +++ \\
\hline TAP block for App/IS & Pain & $24 \mathrm{hr}$ & US & 3 & -2.48 & -4.10 to -0.87 & $P=0.003$ & 0.94 & moderate +++ \\
\hline TAP block for App/IS & Pain & $24 \mathrm{hr}$ & Landmark & 3 & -0.94 & -1.55 to -0.34 & $P<0.001$ & 0.65 & moderate +++ \\
\hline
\end{tabular}

$\mathrm{App} / \mathrm{IS}$ = appendectomy /inguinal surgery; $\mathrm{CD}=$ Cesarean delivery; $\mathrm{CI}$ = confidence interval; $\mathrm{I}^{2}$ = heterogeneity; IAW = inside abdominal wall; $\mathrm{TAP}=$ transversus abdominal plane block; US $=$ ultrasound

Transversus abdominal plane block in gynecological surgery

Eleven studies ${ }^{17,21,26,32,50,51,54,58-61}$ evaluated the efficacy of TAP block in gynecological surgery. Compared with the control group, TAP block reduced the six-hour pain score $^{17,21,26,32,50,51,54}$ by $1.2(95 \% \mathrm{CI},-1.8$ to $-0.6 ; P<$ $0.001)$, the 12 -hr pain score ${ }^{17,21,51}$ by 1.1 (95\% CI, -2.0 to $-0.3 ; P=0.007)$, and the $24-\mathrm{hr}$ pain score by 1.1 (95\% CI, -2.1 to $-0.2 ; P<0.001)$. The TAP block also reduced $24-$ hr morphine consumption ${ }^{17,21,26,50,54,60,61}$ by $5.9 \mathrm{mg}(95 \%$ CI, -8.6 to $-3.1 ; P<0.001$ ) (Fig. 5; Table 2). Only one trial ${ }^{17}$ performed the TAP block from inside the abdominal wall; consequently, it was not possible to perform subgroup analysis for this comparison.

Transversus abdominal plane block in abdominal surgery

In the setting of major abdominal surgery, nine trials were retrieved. ${ }^{16,29,36,38,40-43,52}$ Compared with the control group, TAP block showed no difference in reducing the six-hour pain score ${ }^{16,29,36,38,41,43}(-0.1 ; 95 \% \mathrm{CI},-1.4$ to $1.3 ; P=0.95), 12$-hr pain score ${ }^{16,38,41,52}(1.9,95 \% \mathrm{CI}$, -4.2 to $0.4 ; P=0.11), 24-\mathrm{hr}$ pain score ${ }^{16,29,36,38,41-43,52}$ $(-0.8 ; 95 \% \mathrm{CI},-2.0$ to $0.4 ; P=0.18)$, or 24 -hr morphine consumption $^{16,29,36,38,43,52}(-14.7 \mathrm{mg} ; 95 \% \mathrm{CI},-37.8$ to 8.4; $P=0.21$ ) (Table 2). Only one trial ${ }^{16}$ performed TAP block from inside the abdominal wall; consequently, it was not possible to perform subgroup analysis for this comparison.

Transversus abdominal plane block in appendectomy and inguinal surgery

In inguinal hernia surgery and appendectomy, compared with the control group, the overall analysis showed that the TAP block reduced the six-hour pain score ${ }^{20,30,31,39}$ by 2.5 (95\% CI, -4.7 to $-1.2 ; P=0.001$ ) and the 12 -hr pain score $^{20,30,31,39,48}$ by $3.9(95 \% \mathrm{CI},-5.0$ to $-2.9 ; P<0.001)$ (Fig. 6). Compared with the control group, the TAP block reduced the 24 -hr pain score $20,30,31,39,48,62$ by 1.7 (95\% CI, 


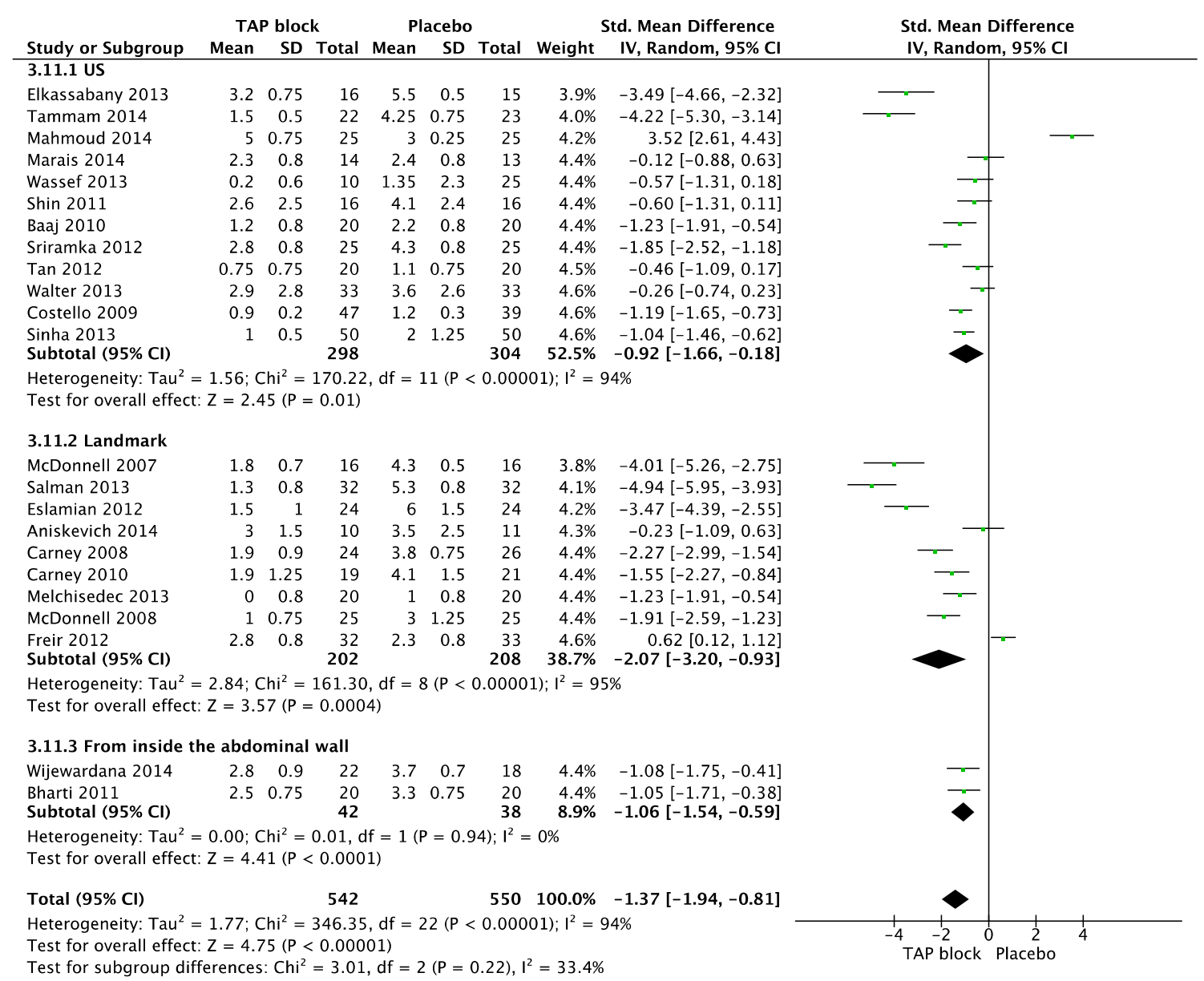

Fig. 2 Forest plot showing the six-hour pain score. The analgesic efficacy of transversus abdominal plane block (TAP) is evaluated in comparison with placebo. The sample size, mean, standard deviation

-2.4 to $-1.0 ; \quad P<0.001)$ and 24-hr morphine consumption $^{30,39,62}$ by $20.4 \mathrm{mg}(95 \% \mathrm{CI},-29.7$ to $-11.1 ; P<0.001$ ) (Table 2).

The 12- and 24-hr US and landmark subanalyses are presented in Table 3. It was not possible to perform subgroup analysis for the six-hour pain score and the 24-hr morphine consumption.

Transversus abdominal plane block in bariatric surgery

There were three studies of TAP block in the setting of bariatric surgery. ${ }^{33,37,63}$ All were laparoscopic procedures (single-port sleeve gastrectomy and gastric bypass surgery) studying the efficacy of TAP block compared with placebo. Transversus abdominal plane block reduced the six-hour pain score by $0.9(95 \% \mathrm{CI},-1.3$ to $-0.5 ; P<0.001)$ and the 12 -hr pain score by 1.1 (95\% CI, -1.6 to $-0.6 ; P<$ $0.001) .^{33,37}$ All trials evaluated $24-\mathrm{hr}$ pain scores and $24-\mathrm{hr}$ morphine consumption. Transversus abdominal plane block did not reduce the $24-\mathrm{hr}$ pain score $(-0.6 ; 95 \% \mathrm{CI}$, -2.1 to $1.0 ; P=0.48)$. In comparison with placebo, TAP
(SD), mean difference, $95 \%$ confidence interval (CI), and heterogeneity are shown

block significantly reduced the 24-hr morphine consumption by $3.8 \mathrm{mg}(95 \% \mathrm{CI},-5.5$ to $-2.2 ; P<$ 0.001) (Table 2). It was not possible to perform subgroup analysis for this comparison.

Transversus abdominal plane block in urologic surgery

In the setting of urologic surgery, including laparoscopic nephrectomy, radical prostatectomy and renal transplantation, we retrieved six articles. ${ }^{19,23,25,40,64,65}$ Transversus abdominal plane block did not reduce sixhour, ${ }^{19,23,25} 12-$ hr $^{19,25,40}$ or 24 -hr pain scores ${ }^{19,23,25,40,65}$ (Table 2). In comparison with placebo, the effect of the TAP block on morphine consumption at $24 \mathrm{hr}^{19,23,25,40}$ was also not significant $(-14.2 \mathrm{mg} ; 95 \% \mathrm{CI},-30.6$ to $2.2 ; P=0.09)$

\section{Discussion}

This systematic review and meta-analysis focused on the efficacy of the TAP block for postoperative analgesia in a 


\begin{tabular}{|c|c|c|c|c|c|c|c|c|c|c|c|c|}
\hline \multirow{3}{*}{$\begin{array}{l}\text { Study or Subgroup } \\
2.11 .1 \text { US }\end{array}$} & \multicolumn{3}{|c|}{ TAP block } & \multicolumn{3}{|c|}{ Placebo } & \multicolumn{2}{|r|}{ Std. Mean Difference } & \multirow{2}{*}{\multicolumn{4}{|c|}{$\begin{array}{l}\text { Std. Mean Difference } \\
\text { IV, Random, } 95 \% \mathrm{CI}\end{array}$}} \\
\hline & Mean & SD & Total & Mean & SD & Total & Weight & IV, Random, 95\% Cl & & & & \\
\hline & & & & & & & & & & & & \\
\hline Aniskevich 2014 & 2.25 & 1.5 & 10 & 4.25 & 2.9 & 11 & $5.5 \%$ & $-0.82[-1.72,0.08]$ & & & & \\
\hline Costello 2009 & 1 & 0.25 & 47 & 1 & 0.2 & 49 & $5.9 \%$ & $0.00[-0.40,0.40]$ & & & - & \\
\hline Mahmoud 2014 & 5 & 1 & 25 & 6 & 0.25 & 25 & $5.8 \%$ & $-1.35[-1.97,-0.73]$ & & - & & \\
\hline Sinha 2013 & 1 & 0.5 & 50 & 2 & 1 & 50 & $5.9 \%$ & $-1.26[-1.69,-0.82]$ & & - & & \\
\hline Soltani 2014 & 1 & 0.2 & 22 & 2.75 & 0.25 & 22 & $4.3 \%$ & $-7.59[-9.36,-5.83]$ & & & & \\
\hline Sriramka 2012 & 2.1 & 0.8 & 25 & 4.2 & 0.8 & 25 & $5.6 \%$ & $-2.58[-3.35,-1.82]$ & & & & \\
\hline Tammam 2014 & 1 & 0.5 & 22 & 4 & 0.5 & 23 & $4.8 \%$ & $-5.89[-7.30,-4.49]$ & & & & \\
\hline Tan 2012 & 0.25 & 0.25 & 20 & 0.9 & 0.5 & 20 & $5.7 \%$ & $-1.61[-2.33,-0.89]$ & & $\rightarrow$ & & \\
\hline $\begin{array}{l}\text { Wassef } 2013 \\
\text { Subtotal }(95 \% \mathrm{Cl})\end{array}$ & 1 & 0.3 & $\begin{array}{r}10 \\
231\end{array}$ & 0.9 & 1.25 & $\begin{array}{r}25 \\
250\end{array}$ & $\begin{array}{r}5.7 \% \\
49.1 \%\end{array}$ & $\begin{array}{r}0.09[-0.64,0.82] \\
-2.13[-3.13,-1.12]\end{array}$ & & & & \\
\hline \multicolumn{13}{|c|}{$\begin{array}{l}\text { Heterogeneity: } \text { Tau }^{2}=2.13 ; \mathrm{Chi}^{2}=153.91, \mathrm{df}=8(\mathrm{P}<0.00001) ; \mathrm{I}^{2}=95 \% \\
\text { Test for overall effect: } Z=4.16(\mathrm{P}<0.0001)\end{array}$} \\
\hline \multicolumn{13}{|l|}{ 2.11.2 Landmark } \\
\hline Carney 2008 & 1.75 & 0.75 & 24 & 3.2 & 0.7 & 26 & $5.7 \%$ & $-1.97[-2.66,-1.28]$ & & & & \\
\hline Carney 2010 & 1.25 & 1.25 & 19 & 3.9 & 1.4 & 21 & $5.6 \%$ & $-1.95[-2.72,-1.18]$ & & & & \\
\hline Eslamian 2012 & 1.25 & 0.75 & 24 & 3 & 1 & 24 & $5.7 \%$ & $-1.95[-2.64,-1.25]$ & & & & \\
\hline Freir 2012 & 2.3 & 0.8 & 32 & 1.9 & 0.8 & 33 & $5.9 \%$ & $0.49[-0.00,0.99]$ & & & $=$ & \\
\hline McDonnell 2008 & 0.6 & 0.7 & 25 & 2.2 & 1.3 & 25 & $5.8 \%$ & $-1.51[-2.14,-0.87]$ & & - & & \\
\hline Melchisedec 2013 & 0 & 0.8 & 32 & 3 & 0.8 & 20 & $5.4 \%$ & $-3.69[-4.62,-2.77]$ & & . & & \\
\hline $\begin{array}{l}\text { Salman } 2013 \\
\text { Subtotal }(95 \% \mathrm{CI})\end{array}$ & 1.2 & 0.8 & $\begin{array}{r}32 \\
188\end{array}$ & 5 & 0.8 & $\begin{array}{r}32 \\
181\end{array}$ & $\begin{array}{r}5.4 \% \\
39.5 \%\end{array}$ & $\begin{array}{l}-4.69[-5.66,-3.72] \\
-2.15[-3.39,-0.91]\end{array}$ & & & & \\
\hline \multicolumn{13}{|c|}{$\begin{array}{l}\text { Heterogeneity: } \mathrm{Tau}^{2}=2.66 ; \mathrm{Chi}^{2}=130.25, \mathrm{df}=6(\mathrm{P}<0.00001) ; \mathrm{I}^{2}=95 \% \\
\text { Test for overall effect: } Z=3.40(P=0.0007)\end{array}$} \\
\hline \multicolumn{13}{|c|}{ 2.11.3 From inside the abdominal wall } \\
\hline Bharti 2011 & 1 & 0.5 & 20 & 2 & 0.5 & 20 & $5.6 \%$ & $-1.96[-2.73,-1.19]$ & & 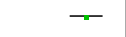 & & \\
\hline $\begin{array}{l}\text { Wijewardana } 2014 \\
\text { Subtotal }(95 \% \mathrm{CI})\end{array}$ & 2.1 & 1 & $\begin{array}{l}22 \\
42\end{array}$ & 3 & 0.9 & $\begin{array}{l}18 \\
38\end{array}$ & $\begin{array}{r}5.7 \% \\
11.4 \%\end{array}$ & $\begin{array}{l}-0.92[-1.58,-0.26] \\
-1.42[-2.44,-0.41]\end{array}$ & & & & \\
\hline \multicolumn{13}{|c|}{$\begin{array}{l}\text { Heterogeneity: } \text { Tau }^{2}=0.41 ; \mathrm{Chi}^{2}=4.05, \mathrm{df}=1(P=0.04) ; \mathrm{I}^{2}=75 \% \\
\text { Test for overall effect: } Z=2.74(P=0.006)\end{array}$} \\
\hline Total $(95 \% \mathrm{Cl})$ & & & 461 & & & 469 & $100.0 \%$ & $-2.04[-2.72,-1.37]$ & & & & \\
\hline \multicolumn{9}{|c|}{$\begin{array}{l}\text { Heterogeneity: } \mathrm{Tau}^{2}=1.94 ; \mathrm{Chi}^{2}=294.50, \mathrm{df} \\
\text { Test for overall effect: } \mathrm{Z}=5.96(\mathrm{P}<0.00001) \\
\text { Test for subgroup differences: } \mathrm{Chi}^{2}=1.19, \mathrm{df}\end{array}$} & -10 & -5 TAP block & Placebo $^{5}$ & 10 \\
\hline
\end{tabular}

Fig. 3 Forest plot showing the 12-hr pain score. The analgesic efficacy of transversus abdominal plane block (TAP) is evaluated in comparison with placebo. The sample size, mean, standard deviation (SD), mean difference, 95\% confidence interval (CI), and heterogeneity are shown

comprehensive group of abdominal surgical procedures. Compared with placebo, when TAP blocks are used for postoperative analgesia, the data show a significant reduction in pain scores at six, 12 , and $24 \mathrm{hr}$ as well as a reduction in 24-hr opioid consumption. Intrathecal morphine seems to decrease opioid consumption better than the TAP block while achieving similar pain scores. Transversus abdominal plane block is also able to decrease opioid consumption compared with local infiltration techniques. When compared with epidural analgesia and IIN blocks, it was not possible to draw a conclusion about the efficacy of TAP blocks due to the scarcity of published studies.

When analyzing the efficiency of TAP block pain control after different types of surgery, it seems most beneficial-in terms of both reduction in pain and opioid consumption-for gynecological surgery, bariatric surgery, and appendectomy and inguinal hernia surgery. It also reduces opioid consumption significantly after Cesarean delivery.

Even if statistically significant, a difference of $<1$ point on a 0-10 VAS scale and a small (e.g., $\leq 5 \mathrm{mg}$ ) reduction in morphine consumption cannot be considered to have great clinical significance. Interestingly, this reduction varied from $4.9 \mathrm{mg}$ (TAP block $v s$ local infiltration) to $10.1 \mathrm{mg}$ in Cesarean delivery and up to $20.4 \mathrm{mg}$ in appendectomy and inguinal surgery (Table 2). Furthermore, we did not consider opioid-induced side effects (i.e., sedation, postoperative nausea and vomiting, respiratory depression, suppressed cough reflex), though a reduction in opioid consumption could lead to a significant clinical improvement in these side effects.

It is also important to underline that the large heterogeneity found might reduce the clinical significance of our results.

Our subgroup analyses on the comparison of the US- vs the landmark-guided technique did not observe a remarkable superiority of one technique over the other. Regardless of the numerous advantages of performing nerve block with US, in our view, the analgesic efficacy of the TAP block is influenced by several other factors, such as the type and dose of anesthetics used, the timing (before/ after the surgery), and the approach (i.e., mid-axillary, subcostal, posterior).

Previously published meta-analyses reported similar results. Mishriky et al. ${ }^{66}$ published a meta-analysis of nine RCTs investigating the efficacy of TAP block for pain control after Cesarean delivery. In that meta-analysis, the 


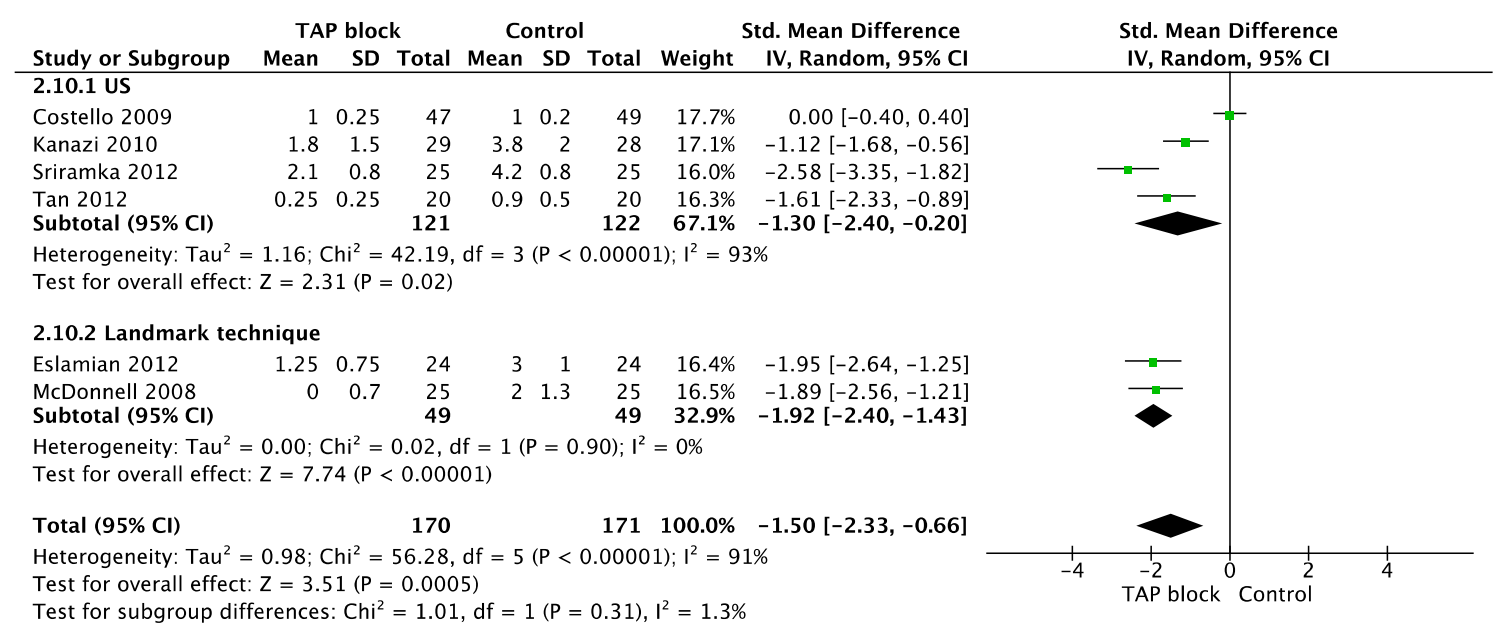

Fig. 4 Forest plot showing the 12-hr pain score. The analgesic efficacy of transversus abdominal plane block (TAP) is evaluated in Cesarean delivery. The control group received saline, no block or intrathecal morphine. The sample size, mean, standard deviation (SD), mean difference, 95\% confidence interval (CI), and heterogeneity are shown

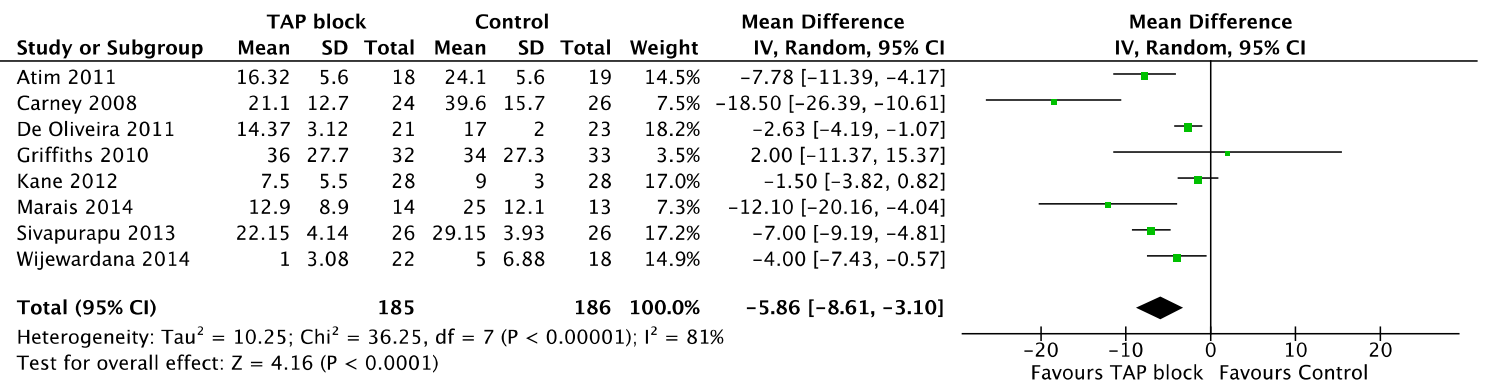

Fig. 5 Forest plot showing the 24-hr morphine consumption. The analgesic efficacy of transversus abdominal plane block (TAP) is evaluated in gynecological surgery. The control group received saline, no block or local infiltration. The sample size, mean, standard deviation (SD), mean difference, $95 \%$ confidence interval (CI), and heterogeneity are shown

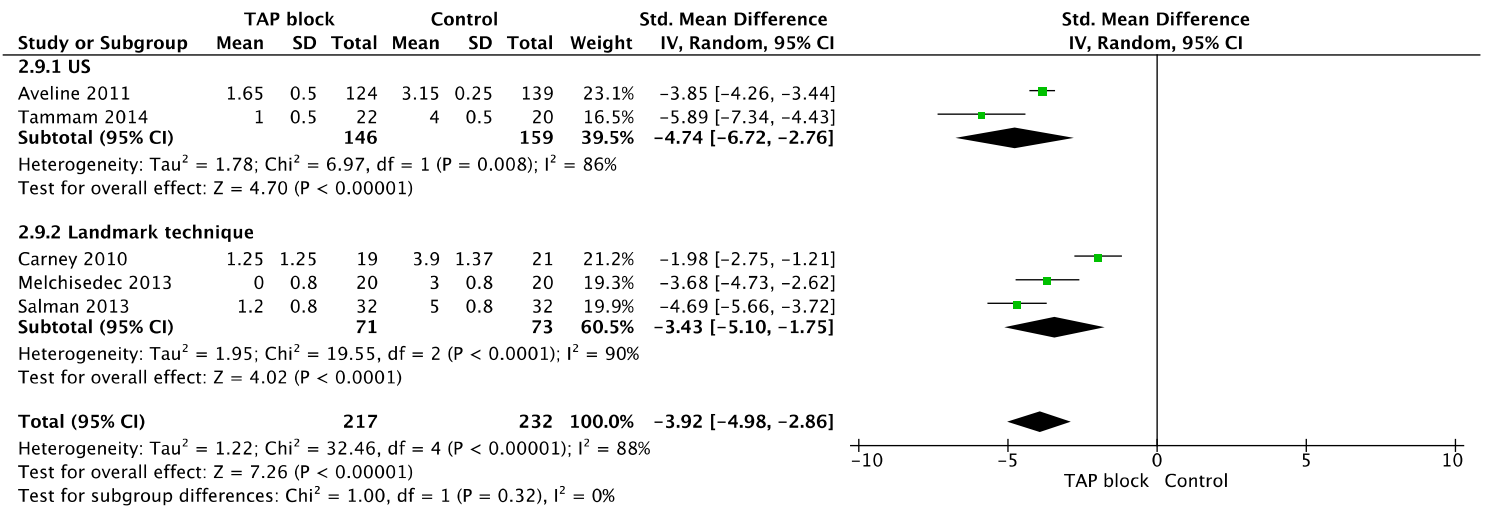

Fig. 6 Forest plot showing the 12-hr pain score. The analgesic efficacy of transversus abdominal plane block (TAP) is evaluated in appendectomy and inguinal surgery. The control group received

authors performed subgroup analysis; they calculated the confidence interval for articles comparing TAP block with placebo separately from the confidence interval for trials comparing TAP block with ITM. The authors concluded saline, no block or ilioinguinal nerve block. The sample size, mean, standard deviation (SD), mean difference, $95 \%$ confidence interval (CI), and heterogeneity are shown

that TAP block improved postoperative analgesia significantly in women undergoing Cesarean delivery who did not receive ITM; whereas, they did not find significant improvement in pain control and morphine 
consumption in patients who received ITM. In our analysis, we obtained similar results. Taken together, this suggests that TAP block might play an important role in patients with contraindications to opioids.

A strength of our meta-analysis compared with prior meta-analyses studying TAP block ${ }^{7,8,66}$ is that prior ones reported a small number of studies limited to specific surgical procedures. Given the increasing number of TAP block studies appearing in the literature, we performed a systematic review and meta-analysis across a wider range of studies. Nevertheless, our meta-analysis does have several limitations. First, it was not possible to obtain data from all the trials included. Some studies used non-opioid drugs for postoperative pain management; others did not collect data at $24 \mathrm{hr}$ after surgery, and others did not use the VAS score to report pain. Second, the overwhelming majority of studies retrieved focused on the comparison of TAP block with placebo. Few studies focused on the comparison with other anesthetic techniques (e.g., epidural analgesia). There is still a need for more studies comparing TAP block with other analgesic techniques in a large cohort of patients.

An additional limitation is that we observed a high degree of heterogeneity between the studies. This likely reflects the different types of surgical procedures, differences in the choice of local anesthetic used and in the dose administered. Similarly, the differences among the patients (e.g., age, comorbidities) and interventions (e.g., type of block, timing, postoperative analgesia) may have played an important role in increasing heterogeneity. Both single-injection and continuous TAP blocks provide postoperative analgesia; however ${ }^{67}$ the two techniques may have had a different impact on the postoperative VAS score. Transversus abdominal plane block is an operator-dependent procedure that can be performed following different approaches. Since Rafi's classic description, ${ }^{1}$ a growing number of studies appeared in the literature showing different new techniques to perform the TAP block (e.g., oblique subcostal approach). ${ }^{68}$ As suggested in some cadaveric studies, ${ }^{2-4}$ the spread of local anesthetic is influenced by the approach used. Moreover, a 2013 systematic review and meta-analysis ${ }^{69}$ showed that the posterior TAP block technique determined a greater reduction in opioid consumption and in rest and dynamic pain scores compared with the lateral approaches. Lastly, performing the TAP block before the procedure (i.e., preemptive analgesia) or at the end of the surgery may have had an important clinical impact on the analgesic control.

During the conduct of this review and meta-analysis, we identified some areas for future research. It would be useful to continue to investigate the efficacy of TAP blocks for pain management in comparison with epidural and IIN nerve blocks. Future studies could also focus on the influence of timing of the block and type and concentration of local anesthetic drug administered (i.e., dose-ranging studies).

Based on our findings, the best recommendation (i.e., improved pain score and decreased opioid consumption) for using TAP block for postoperative analgesia is in gynecological procedures, bariatric surgery, appendectomy, and inguinal hernia repair.

It can also be recommended for Cesarean delivery (i.e., because of a decrease in opioid consumption). There is as yet no valid recommendation for its potential to decrease pain or opioid consumption in abdominal surgery in general or urological procedures.

Even if TAP block is not as effective as ITM or epidural analgesia, TAP block might be used to provide analgesia when neuraxial techniques or opioids are contraindicated. Future RCTs are needed to compare the efficacy of TAP block with epidural or IIL nerve block.

Funding No external funding and no conflicts of interest declared.

Author Contributions Etrusca Brogi was involved in data analysis and writing the first draft. Thomas M. Hemmerling, Roy Kazan, and Shantale Cyr were involved in the revision of the manuscript. Francesco Giunta was involved in the control of data and figures. Thomas M. Hemmerling was involved in the idea for the study and final approval.

Editorial responsibility This submission was handled by Dr. Hilary P. Grocott, Editor-in-Chief, Canadian Journal of Anesthesia.

\section{References}

1. Rafi AN. Abdominal field block: a new approach via the lumbar triangle. Anaesthesia 2001; 56: 1024-6.

2. Milan Z, Tabor D, McConnell P, et al. Three different approaches to transversus abdominis planeblock: a cadaveric study. Med Glas (Zenica) 2011; 8: 181-4.

3. Tran TM, Ivanusic JJ, Hebbard P, Barrington MJ. Determination of spread of injectate after ultrasound-guided transversus abdominis plane block: a cadaveric study. Br J Anaesth 2009; 102: 123-7.

4. Barrington MJ, Ivanusic JJ, Rozen WM, Hebbard P. Spread of injectate after ultrasound-guided subcostal transversus abdominis plane block: a cadaveric study. Anaesthesia 2009; 64: 745-50.

5. Charlton S, Cyna AM, Middleton P, Griffiths JD. Perioperative transversus abdominis plane (TAP) blocks for analgesia after abdominal surgery. Cochrane Database Syst Rev 2010 12: CD007705.

6. Abdallah FW, Halpern SH, Margarido CB. Transversus abdominis plane block for postoperative analgesia after caesarean delivery performed under spinal anaesthesia? A systematic review and meta-analysis. Br J Anaesth 2012; 109: 679-87.

7. Champaneria R, Shah L, Geoghegan J, Gupta JK, Daniels JP. Analgesic effectiveness of transversus abdominis plane blocks after hysterectomy: a meta-analysis. Eur J Obstet Gynecol Reprod Biol 2013; 166: 1-9. 
8. De Oliveira GS, Jr Castro-Alves LJ, Nader A, Kendall MC, McCarthy RJ. Transversus abdominis plane block to ameliorate postoperative pain outcomes after laparoscopic surgery: a metaanalysis of randomized controlled trials. Anesth Analg 2014; 118 : 454-63.

9. Liberati A, Altman DG, Tetzlaff $J$, et al. The PRISMA statement for reporting systematic reviews and meta-analyses of studies that evaluate health care interventions: explanation and elaboration. Ann Intern Med 2009; 151: W-65-94.

10. Moher D, Jadad AR, Nichol G, Penman M, Tugwell P, Walsh S. Assessing the quality of randomized controlled trials: an annotated bibliography of scales and checklists. Control Clin Trials 1995; 16: 62-73.

11. Hozo SP, Djulbegovic B, Hozo I. Estimating the mean and variance from the median, range, and the size of a sample. BMC Med Res Methodol 2005; 5: 13.

12. Chou R, Fanciullo GJ, Fine PG, et al. Clinical guidelines for the use of chronic opioid therapy in chronic noncancer pain. J Pain 2009; 10: 113-30.

13. Pereira J, Lawlor P, Vigano A, Dorgan $M$, Bruera E. Equianalgesic dose ratios for opioids. A critical review and proposals for long-term dosing. J Pain Symptom Manage 2001; 22: 672-87.

14. Egger M, Davey Smith $G$, Schneider M, Minder C. Bias in metaanalysis detected by a simple, graphical test. BMJ 1997; 315: 629-34.

15. Higgins JP, Green S. Cochrane Handbook for Systematic Reviews of Interventions: Wiley Online Library; 2008.

16. Bharti N, Kumar P, Bala I, Gupta V. The efficacy of a novel approach to transversus abdominis plane block for postoperative analgesia after colorectal surgery. Anesth Analg 2011; 112: 1504-8.

17. Wijewardana $M G$, Pathiraja $R$, Jayawardane $M A$. The analgesic efficacy of transversus abdominis plane (TAP) block after total abdominal hysterectomy: a randomized controlled trial. Sri Lanka J Obstet Gynaecol 2014; 36: 5-10.

18. Sforza $M$, Andjelkov $K$, Zaccheddu $R$, Nagi $H$, Colic $M$. Transversus abdominis plane block anesthesia in abdominoplasties. Plast Reconstr Surg 2011; 128: 529-35.

19. Aniskevich S, Taner CB, Perry DK, et al. Ultrasound-guided transversus abdominis plane blocks for patients undergoing laparoscopic hand-assisted nephrectomy: a randomized, placebo-controlled trial. Local Reg Anesth 2014; 7: 11-6.

20. Carney J, Finnerty O, Rauf J, Curley G, McDonnell JG, Laffey $J G$. Ipsilateral transversus abdominis plane block provides effective analgesia after appendectomy in children: a randomized controlled trial. Anesth Analg 2010; 111: 998-1003.

21. Carney J, McDonnell JG, Ochana A, Bhinder R, Laffey JG. The transversus abdominis plane block provides effective postoperative analgesia in patients undergoing total abdominal hysterectomy. Anesth Analg 2008; 107: 2056-60.

22. Costello JF, Moore AR, Wieczorek PM, Macarthur AJ, Balki M, Carvalho JC. The transversus abdominis plane block, when used as part of a multimodal regimen inclusive of intrathecal morphine, does not improve analgesia after cesarean delivery. Reg Anesth Pain Med 2009; 34: 586-9.

23. Elkassabany N, Ahmed M, Malkowicz SB, Heitjan DF, Isserman $J A$, Ochroch EA. Comparison between the analgesic efficacy of transversus abdominis plane (TAP) block and placebo in open retropubic radical prostatectomy: a prospective, randomized, double-blinded study. J Clin Anesth 2013; 25: 459-65.

24. Eslamian L, Jalili Z, Jamal A, Marsoosi V, Movafegh A. Transversus abdominis plane block reduces postoperative pain intensity and analgesic consumption in elective cesarean delivery under general anesthesia. J Anesth 2012; 26: 334-8.

25. Freir NM, Murphy C, Mugawar M, Linnane A, Cunningham AJ. Transversus abdominis plane block for analgesia in renal transplantation: a randomized controlled trial. Anesth Analg 2012; 115: 953-7.

26. Marais A, Porrill $O$, James MF, Dyer RA. The use of ultrasoundguided transverses abdominis plane blocks for total abdominal hysterectomy: a double-blind, controlled trial. South Afr J Anaesth Analg 2013; 20: 117-21.

27. Baaj JM, Alsatli RA, Majaj HA, Babay ZA, Thallaj AK. Efficacy of ultrasound-guided transversus abdominis plane (TAP) block for postcesarean section delivery analgesia-a double-blind, placebo-controlled, randomized study. Middle East J Anaesthesiol 2010; 20: 821-6.

28. McDonnell JG, Curley G, Carney J, et al. The analgesic efficacy of transversus abdominis plane block after cesarean delivery: a randomized controlled trial. Anesth Analg 2008; 106: 186-91.

29. McDonnell JG, O'Donnell B, Curley $G$, Heffernan A, Power $C$, Laffey $J G$. The analgesic efficacy of transversus abdominis plane block after abdominal surgery: a prospective randomized controlled trial. Anesth Analg 2007; 104: 193-7.

30. Melchisedec AL, Varghese AG, Verghese $V$. Transversus abdominis plane (TAP) block reduces postoperative morhpine requirement and postoperative sedation scores in patients undergoing lower abdominal surgery. Journal of Evolution of Medical and Dental Sciences 2013; 2: 3232-8.

31. Salman AE, Yetişir F, Yurekli B, Aksoy M, Yildirim M, Kiliç M. The efficacy of the semi-blind approach of transversus abdominis plane block on postoperative analgesia in patients undergoing inguinal hernia repair: a prospective randomized double-blind study. Local Reg Anesth 2013; 6: 1-7.

32. Shin HJ, Kim ST, Yim KH, Lee HS, Sim JH, Shin YD. Preemptive analgesic efficacy of ultrasound-guided transversus abdominis plane block in patients undergoing gynecologic surgery via a transverse lower abdominal skin incision. Korean J Anesthesiol 2011; 61: 413-8.

33. Sinha A, Jayaraman L, Punhani D. Efficacy of ultrasound-guided transversus abdominis plane block after laparoscopic bariatric surgery: a double blind, randomized, controlled study. Obes Surg 2013; 23: 548-53.

34. Sriramka B, Sahoo N, Panigrahi S. Analgesic efficacy of ultrasound-guided transversus abdominis plane block following caesarean section. International Journal of Perioperative Ultrasound and Applied Technologies 2012; 1: 5-8.

35. Tan TT, Teoh WH, Woo DC, Ocampo CE, Shah MK, Sia AT. A randomised trial of the analgesic efficacy of ultrasound-guided transversus abdominis plane block after caesarean delivery under general anaesthesia. Eur J Anaesthesiol 2012; 29: 88-94.

36. Walter CJ, Maxwell-Armstrong C, Pinkney TD, et al. A randomised controlled trial of the efficacy of ultrasound-guided transversus abdominis plane (TAP) block in laparoscopic colorectal surgery. Surg Endosc 2013; 27: 2366-72.

37. Wassef $M$, Lee DY, Levine JL, et al. Feasibility and analgesic efficacy of the transversus abdominis plane block after single-port laparoscopy in patients having bariatric surgery. J Pain Res 2013; 6: 837-41.

38. Serag Eldin M, Mahmoud F, El-Hassan R, et al. Intravenous patient-controlled fentanyl with and without transversus abdominis plane block in cirrhotic patients post liver resection. Local Reg Anesth 2014; 7: 27-37.

39. Tammam TF. Transversus abdominis plane block: the analgesic efficacy of a new block catheter insertion method. Egypt J Anaesth 2014; 30: 39-45.

40. Soltani Mohammadi S, Dabir A, Shoeibi G. Efficacy of transversus abdominis plane block for acute postoperative pain relief in kidney recipients: a double-blinded clinical trial. Pain Med 2014; 15: 460-4.

41. Niraj G, Kelkar A, Hart E, et al. Comparison of analgesic efficacy of four-quadrant transversus abdominis plane (TAP) 
block and continuous posterior TAP analgesia with epidural analgesia in patients undergoing laparoscopic colorectal surgery: an open-label, randomised, non-inferiority trial. Anaesthesia 2014; 69: 348-55.

42. Niraj G, Kelkar A, Jeyapalan I, et al. Comparison of analgesic efficacy of subcostal transversus abdominis plane blocks with epidural analgesia following upper abdominal surgery. Anaesthesia 2011; 66: 465-71.

43. Wu $Y$, Liu F, Tang $H$, et al. The analgesic efficacy of subcostal transversus abdominis plane block compared with thoracic epidural analgesia and intravenous opioid analgesia after radical gastrectomy. Anesth Analg 2013; 117: 507-13.

44. Kanazi GE, Aouad MT, Abdallah FW, et al. The analgesic efficacy of subarachnoid morphine in comparison with ultrasound-guided transversus abdominis plane block after cesarean delivery: a randomized controlled trial. Anesth Analg 2010; 111: 475-81.

45. Lee AJ, Palte HD, Chehade JM, Arheart KL, Ranasinghe JS, Penning $D H$. Ultrasound-guided bilateral transversus abdominis plane blocks in conjunction with intrathecal morphine for postcesarean analgesia. J Clin Anesth 2013; 25: 475-82.

46. Loane H, Preston R, Douglas MJ, Massey S, Papsdorf M, Tyler J. A randomized controlled trial comparing intrathecal morphine with transversus abdominis plane block for post-cesarean delivery analgesia. Int J Obstet Anesth 2012; 21: 112-8.

47. McMorrow RC, Ni Mhuircheartaigh RJ, Ahmed KA, et al. Comparison of transversus abdominis plane block vs spinal morphine for pain relief after caesarean section. Br J Anaesth 2011; 106: 706-12.

48. Aveline C, Le Hetet H, Le Roux A, et al. Comparison between ultrasound-guided transversus abdominis plane and conventional ilioinguinal/iliohypogastric nerve blocks for day-case open inguinal hernia repair. Br J Anaesth 2011; 106: 380-6.

49. Fredrickson MJ, Paine $C$, Hamill J. Improved analgesia with the ilioinguinal block compared to the transversus abdominis plane block after pediatric inguinal surgery: a prospective randomized trial. Paediatr Anaesth 2010; 20: 1022-7.

50. Atim A, Bilgin $F$, Kilickaya $O$, et al. The efficacy of ultrasoundguided transversus abdominis plane block in patients undergoing hysterectomy. Anaesth Intensive Care 2011; 39: 630-4.

51. Omar AM. Postoperative continuous transversus abdominis plane block vs continuous wound infusion of levobupivacaine in females undergoing open gynecologic procedures. Egypt J Anaesth 2013; 29: 383-8.

52. Ortiz J, Suliburk $J W, W u K$, et al. Bilateral transversus abdominis plane block does not decrease postoperative pain after laparoscopic cholecystectomy when compared with local anesthetic infiltration of trocar insertion sites. Reg Anesth Pain Med 2012; 37: 188-92.

53. Sahin L, Sahin $M$, Gul R, Saricicek V, Isikay N. Ultrasoundguided transversus abdominis plane block in children: a randomised comparison with wound infiltration. Eur $\mathbf{J}$ Anaesthesiol 2013; 30: 409-14.

54. Sivapurapu V, Vasudevan A, Gupta S, Badhe AS. Comparison of analgesic efficacy of transversus abdominis plane block with direct infiltration of local anesthetic into surgical incision in lower abdominal gynecological surgeries. J Anaesthesiol Clin Pharmacol 2013; 29: 71-5.
55. Tolchard S, Davies $R$, Martindale $S$. Efficacy of the subcostal transversus abdominis plane block in laparoscopic cholecystectomy: comparison with conventional port-site infiltration. J Anaesthesiol Clin Pharmacol 2012; 28: 339-43.

56. Belavy D, Cowlishaw PJ, Howes M, Phillips F. Ultrasoundguided transversus abdominis plane block for analgesia after caesarean delivery. Br J Anaesth 2009; 103: 726-30.

57. McKeen DM, George RB, Boyd JC, Allen VM, Pink A. Transversus abdominis plane block does not improve early or late pain outcomes after cesarean delivery: a randomized controlled trial. Can J Anesth 2014; 61: 631-40.

58. Calle GA, Lopez CC, Sanchez E, et al. Transversus abdominis plane block after ambulatory total laparoscopic hysterectomy: randomized controlled trial. Acta Obstet Gynecol Scand 2014; 93: 345-50.

59. De Oliveira GS, Jr Milad MP, Fitzgerald $P$, Rahmani $R$, McCarthy RJ. Transversus abdominis plane infiltration and quality of recovery after laparoscopic hysterectomy: a randomized controlled trial. Obstet Gynecol 2011; 118: 1230-7.

60. Griffiths JD, Middle JV, Barron FA, Grant SJ, Popham PA, Royse $C F$. Transversus abdominis plane block does not provide additional benefit to multimodal analgesia in gynecological cancer surgery. Anesth Analg 2010; 111: 797-801.

61. Kane SM, Garcia-Tomas V, Alejandro-Rodriguez, M, Astley B, Pollard RR. Randomized trial of transversus abdominis plane block at total laparoscopic hysterectomy: effect of regional analgesia on quality of recovery. Am J Obstet Gynecol 2012; 207: 419.e1-5.

62. Niraj $G$, Searle A, Mathews $M$, et al. Analgesic efficacy of ultrasound-guided transversus abdominis plane block in patients undergoing open appendicectomy. Br J Anaesth 2009; 103: 6015 .

63. Albrecht E, Kirkham KR, Endersby RV, et al. Ultrasound-guided transversus abdominis plane (TAP) block for laparoscopic gastric-bypass surgery: a prospective randomized controlled double-blinded trial. Obes Surg 2013; 23: 1309-14.

64. Al-Sadek WM, Rizk SN, Selim MA. Ultrasound guided transversus abdominis plane block in pediatric patients undergoing laparoscopic surgery. Egypt J Anaesth 2014; 30: 273-8.

65. Hosgood SA, Thiyagarajan UM, Nicholson HF, Jeyapalan I, Nicholson $M L$. Randomized clinical trial of transversus abdominis plane block versus placebo control in live-donor nephrectomy. Transplantation 2012; 94: 520-5.

66. Mishriky BM, George RB, Habib AS. Transversus abdominis plane block for analgesia after cesarean delivery: a systematic review and meta-analysis. Can J Anesth 2012; 59: 766-78.

67. Hotta $K$, Inoue $S$, Taira $K$, Sata $N$, Tamai $K$, Takeuchi $M$. Comparison of the analgesic effect between continuous wound infiltration and single-injection transversus abdominis plane block after gynecologic laparotomy. J Anesth 2016; 30: 31-8.

68. Hebbard $P$. Subcostal transversus abdominis plane block under ultrasound guidance. Anesth Analg 2008; 106: 674-5.

69. Abdallah FW, Laffey JG, Halpern SH, Brull R. Duration of analgesic effectiveness after the posterior and lateral transversus abdominis plane block techniques for transverse lower abdominal incisions: a meta-analysis. Br J Anaesth 2013; 111: 721-35. 